\title{
MÍDIA E POLÍTICAS PÚBLICAS: \\ Possíveis campos exploratórios
}

\section{Claudio Camargo Penteado Ivan Fortunato}

DOI: http//dx.doi.org/10.17666/3087129-141/2015

\section{Introduçáo}

Os escritos de Thompson (1998), entre outros, revelam que há expressiva centralidade da mídia nas relaçóes sociais contemporâneas, o que confere aos meios de comunicação um importante papel nas dinâmicas sociais. De fato, não são poucos os estudos que garantem tal aporte fundamental, como demonstra, por exemplo, Antonio Rubim (2001), ao assinalar que há pelo menos oito conceitos amplamente citados pela comunidade acadêmica preocupada com questóes sociais que conferem tal poder à mídia: aldeia global, de Marshall McLuhan; Era da Informaçãoo, de Manuel Castells; sociedade informática, de Adan Schaff; sociedade da informação, de David Lyon; sociedade da informação ou da comunicação, de Ismar de Oliveira

Aprovado em 28/11/2014
Soares; sociedade media-centric, de Venício Lima; e planeta midia, de Dênis de Moraes. E há, ainda, o conceito do próprio Rubim (2000): Idade Mídia.

A influência da mídia é percebida em diversos campos da atividade humana, dentre eles a política. Apesar de o campo político apresentar uma configuração específica, com regras e capitais próprios, como explica Miguel (2002), os meios de comunicação também interferem nas práticas políticas, criando uma dinâmica própria dentro do jogo: os veículos de comunicação tornam-se novos espaços de disputa e novas ferramentas de persuasão, além de incorporar outros atores nos pleitos políticos. $\mathrm{Na}$ sociedade contemporânea ou, nos termos de Castells (2009), na sociedade em rede, o poder da comunicação é central dentro da disputa política, principalmente por sua capacidade de produção de sentidos e significados. 
No âmbito governamental, as políticas públicas (doravante referidas apenas como $\mathrm{PP}$ ) são mecanismos de ação do Estado sobre a sociedade, de forma que a administração pública, por meio de seus agentes, atua sobre determinadas questóes com a finalidade de promover o desenvolvimento social (Souza, 2006; Frey, 2000). Geralmente, explica Souza (2006), os estudos sobre PP focam suas análises sobre os procedimentos institucionais, o processo decisório e/ou suas avaliações, adotando um viés gerencialista. Essa abordagem, de acordo com Subirats (2008), enxerga as variáveis endógenas ao sistema de PP como pouco relevantes no processo, privilegiando a ação dos especialistas na tomada das decisões (processo decisório), visando alcançar maior eficiência-eficácia-efetividade, ou, então, os estudos mostram-se preocupados com a atuação dos atores políticos no âmbito do processo decisório das PP.

Apesar de as abordagens existentes no estudo das PP permitirem que a mídia, através dos meios de comunicação de massa e, mais recentemente, por meio das novas tecnologias de informação e comunicação (TICs), seja compreendida como um fator que pode exercer alguma influência sobre as $\mathrm{PP}$, há poucos estudos (teóricos e empíricos) com esse enfoque. Com exceção dos estudos de Walter Lippmann (1997), nos anos de 1920, parece que a ciência política não dá muita importância para o tema, preferindo focar suas análises nas instituiçôes políticas e nos processos decisórios, sendo que, no Brasil, essa abordagem é quase inexistente, demonstrando importante lacuna a ser preenchida nesse campo de conhecimento.

Este artigo é motivado por um corolário que sustenta a mídia como importante fator político e espaço de ação política na sociedade contemporânea, influente na dinâmica dos fenômenos sociais. Assim, a questão central que levantamos neste artigo é se a mídia exerce algum tipo de influência no curso das PP. E, em caso positivo, de que forma age/agiria? Este trabalho faz parte de uma pesquisa mais ampla que objetiva analisar com profundidade essa possível relação entre mídia e PP. Aqui, o objetivo profícuo é apresentar uma revisão de literatura e indicar caminhos teóricos da aproximação entre o campo midiático e o das PP.

\section{Breve histórico das políticas públicas}

O Estado tem o papel de agente promotor e é responsável pela criação, desenvolvimento e implantação das PP. Contudo, ele é permeável a influências internas (dos seus agentes, da burocracia, das normas institucionais, da acomodação de interesses políticos etc.), e externas (movimentos populares, grupos de interesses, mídia etc.). A atividade de governar e de formular PP é complexa, pois, além das influências (internas e externas), também é afetada pelos fatores estruturais, pela cultura política e até mesmo pela conjuntura política (interna e internacional).

Nesse sentido, acreditar nas PP como um mero mecanismo técnico de intervenção estatal é ingênuo, uma vez que tal afirmação não reconhece a complexidade de fatores que vão interferir em sua formulação, execução e avaliação, assim como o jogo político e os arranjos que as cercam, que vão além dos procedimentos institucionais. Essa abordagem reducionista e simplista acaba por limitar a percepção sobre as PP. Em muitos casos, as PP podem ser utilizadas não apenas para a promoção do desenvolvimento social ou melhoria da forma de atuação estatal, mas para a formação de capital político e atendimento de interesses de grupos específicos, elementos típicos de atuação do campo político.

O campo de conhecimento das PP, explica Celina Souza (2006), nasceu nos Estados Unidos como um desmembramento de teorias explicativas sobre o papel do Estado e do governo na condução política da sociedade. Seu rompimento propóe uma ênfase mais prática voltada para estudos sobre a ação do governo, estruturados no seguinte pressuposto: "o que o governo faz pode ser formulado cientificamente e analisado por pesquisadores independentes”. $\mathrm{Na}$ área governamental, explica a autora, as PP surgem como ferramentas da Guerra Fria e da valorização da tecnocracia, com a formação dos think tanks, sob a influência da Teoria dos Jogos de Neuman.

Em sua revisão da literatura, Souza (2006) indica que existem quatro fundadores da área de $\mathrm{PP}$, que orientaram as abordagens iniciais sobre o tema: 1) Harold Laswell, nos anos de 1930, introduziria a expressão policy analysis (termo inglês para 
designar a análise de PP), de forma a combinar o conhecimento científico com a produção empírica dos governos; 2) posteriormente, Herbert Simon, nos anos de 1950, afirmaria que a racionalidade dos tomadores de decisão é sempre limitada por problemas (de informação incompleta e imperfeita, tempo para tomada de decisão, autointeresse dos decisores etc.), mas que pode ser maximizada pela criação de estruturas que modelem o comportamento dos atores envolvidos; 3) Charles Lindblom questionaria tais abordagens e proporia a incorporação de novas variáveis à formulação e análise de PP: relaçóes de poder (policy network e policy arena) e a integraçáo entre as diferentes fases do processo decisório - nessa concepção, os estudos sobre as PP precisariam acrescentar novos elementos que influenciem sua formulação, implantação e execução para além de uma realidade causal previamente decidida por técnicos governamentais, tais como o papel das eleiçôes, das burocracias e dos partidos, bem como das demandas de grupos de interesse, e aqui podemos destacar o papel da pressão da cobertura da mídia, que acaba também exercendo influência (indireta) sobre o ciclo das PP; 4) por fim, David Easton sugere que o campo de PP deve ser visto como um sistema, como uma relação entre formulação, resultados e ambiente, em que as PP recebem inputs dos partidos, da mídia (influência direta) e de grupos de interesse que vão influenciar seus resultados e efeitos.

Pode-se perceber que, pela leitura de Souza (2006), tanto Lindblom como Easton propóem uma visão mais complexa das $\mathrm{PP}$, entendendo que existem interaçôes que se influenciam mutuamente, causando modificaçóes no desenho imaginado inicialmente, rompendo com a racionalidade linear que poderia haver em sua concepção original. Um dos elementos que pode influenciar (diretamente ou indiretamente) desde a sua formulação até os resultados é a atuação da mídia, que pode agendar temas de grande pressão da sociedade ou mesmo servir de espaço para a avaliaçáo pública de determinadas políticas setoriais, intervindo na percepção e/ou avaliação popular de determinada PP. E, conforme argumentamos adiante, também pode servir de espaço para um debate público sobre PP em todas suas fases, com consultas à população.
No Brasil, o debate sobre PP ganhou destaque na agenda de pesquisas, principalmente a partir dos anos 1980. Souza (2006) identifica três movimentos no âmbito político e estatal que influenciaram esses estudos: 1) a adoçâo de políticas restritivas de gastos; 2) o surgimento de uma nova concepção de atuação do governo, marcada pela diminuição da intervençáo estatal e pelas mudanças do caráter universalista das PP para uma ação focalizada; e 3) a falta de coalizóes políticas para o desenho de PP direcionadas para o desenvolvimento social, principalmente em países emergentes. Além desses, com bases nos estudos de Farah (2007) sobre os arranjos institucionais brasileiros, podemos identificar outro movimento: a incorporação de novas demandas e atores no ciclo das PP, principalmente a partir do processo de redemocratização e da promulgação da Constituição de 1988.

Farah (2007) indica que, no Brasil, o grande marco para a mudança das características das PP foi a Constituição de 1988. As reformas introduzidas, explica a autora, permitiram a mudança do perfil das políticas brasileiras, que até então se caracterizavam pela centralização decisória e financeira na esfera pessoal, que tendia para o estabelecimento de relaçóes baseadas em trocas de favores de cunho clientelista, pela fragmentação institucional com a sobreposição de agências públicas e a exclusão da sociedade civil do processo de formulação das políticas, da implementaçáo dos programas e do controle da açáo estatal. A Constituição de 1988 incorporou os eixos da democratização dos processos decisórios e a equidade dos resultados das $\mathrm{PP}$, privilegiando os princípios de descentralização como uma forma de empoderamento da sociedade e da participaçáo dos cidadãos de modo a aumentar a eficiência da açáo do Estado. Nos anos de 1990, sob impacto da crise fiscal, a falta de recursos passou a ser um fator limitante para a ação do Estado, em que pese o aumento da demanda social. Nesse sentido, Farah (2007) explica que na agenda de PP brasileiras foram inseridas preocupaçôes com a eficiência, eficácia e efetividade das políticas.

Nessa nova formatação, ocorre uma disputa entre duas visōes: a primeira, a perspectiva neoliberal, vê o Estado como ineficiente, sendo necessário desmantelá-lo e garantir a abertura para a açáo do 
mercado pela privatização dos serviços públicos, descentralização de políticas sociais para as esferas locais, determinação de prioridades de ação e mudanças no sistema de gestão dos programas públicos; a segunda, a visão da democratização do Estado, defende a reforma da ação estatal (incorporando alguns dos princípios neoliberais), adequando suas práticas e formas de ação aos novos desafios, promovendo formas distintas de articulação com a sociedade civil e com o setor privado, passando o Estado a atuar como coordenador e fiscalizador de serviços que podem ser prestados pela sociedade civil, pelo mercado ou através de parcerias.

Nessas duas abordagens, prevalece a ideia de reforma das práticas estatais de maneira que torne sua ação mais eficiente e melhore a gestão da administração pública. Nesse movimento de reforma, podemos destacar dois pontos: a aproximação entre prestadores de serviços com os cidadãos-usuários e o estímulo a inovaçôes, de forma a combater as barreiras da burocracia excessiva, a falta de recursos e de controles.

De acordo com Lima (2000), sendo o Brasil uma sociedade em que os meios de comunicação possuem uma posição central nas relações sociais, a atuação dos seus veículos é relevante na configuração do jogo político e no exercício da hegemonia. Os discursos dos diversos atores políticos buscam, nos canais da mídia, espaço para legitimarem-se e ganharem força política perante a opinião pública. A visibilidade midiática das PP nos noticiários e seu enquadramento, ou mesmo da agenda política, são fatores que exercem influência (direta ou indireta) sobre os diferentes atores políticos que atuam no ciclo das PP.

Atualmente, há duas perspectivas para estudo das PP: a abordagem neoinstitucionalista e a análise de estilos políticos. Segundo Souza (2006) e Frey (2000), a abordagem neoinstucionalista compreende as instituiçóes de uma forma mais ampla, abarcando os diversos atores institucionais (burocracia estatal, tomadores de decisão, grupos de interesse, etc.) que participam do ciclo das PP, enfatizando a importância das instituições para a decisão, formulação e implementação de PP. Segundo essa linha teórica, a luta pelos recursos é intermediada pelas instituiçóes políticas e econômicas que direcio- nam o sentido da ação da PP. De acordo com Frey (2000), essa vertente tem dominado os estudos da área no Brasil, abrindo pouco espaço para outras abordagens. Não obstante, ainda que com pouca expressão, devemos considerar a abordagem de estudo com base na análise de estilos políticos. Esse tipo de análise, explica Frey (2000), está voltado para identificar "como" fatores culturais e padróes de comportamento político (clientelismo, paternalismo, corrupção etc.) repercutem na qualidade dos programas e projetos políticos implantados pelos governos.

Em ambas as perspectivas, é possível verificar a importância da mídia como variável de influência sobre o ciclo da PP. Na abordagem neoinstitucionalista, é plausível entender os canais de comunicação como espaço de visibilidade e legitimação dos atores políticos envolvidos no processo das PP, inclusive como mecanismo de pressão sobre os atores institucionais. No segundo caso, os veículos da mídia podem exercer influência (direta ou indireta) no ciclo das PP, tendo em vista seu potencial de ingerência cultural na sociedade contemporânea (cf. Thompson, 1998; Castells, 1999) e comportamento político dos cidadãos (cf. Lima, 2000).

\section{Mídia e política}

Conforme visto, o debate acerca de PP tem dominado grande parte da agenda das ciências sociais, especialmente porque estamos vivendo um momento de reorganização do papel do Estado e suas formas de intervenção (ou não), sendo que diversos estudos e abordagens sobre a temática estão sendo desenvolvidos. Contudo, ainda existem poucos estudos voltados para estudar a influência da mídia sobre as PP, preservando-se, principalmente, uma tendência institucionalista, mesmo por parte das novas abordagens que pretendem dar conta da complexidade que envolve todo o ciclo das PP.

Com o rápido desenvolvimento dos meios de comunicação e a convergência tecnológica dos meios de comunicação e informação, ampliou-se a capacidade de intervenção da mídia nas atividades humanas. Hoje, as diferentes mídias fazem parte, direta ou indiretamente, do cotidiano da maioria da 
populaçáo, seja como fonte de trabalho, fonte de informação, entretenimento e/ou mecanismo de comunicação/interação social. Nesse contexto, a mídia assume centralidade na vida humana, tornando-se, conforme Lima (2000, p. 176), "palco e objeto privilegiado das disputas pelo poder político na contemporaneidade".

A partir da expansão e consolidação da infraestrutura de comunicação no Brasil, Lima (2000) caracteriza o país como uma sociedade media-centered. Através dos veículos de comunicação, as ideias, ações e discursos ganham importância (conhecimento) perante a sociedade, criando espaços de disputas simbólicas (discurso político) que a afetam como um todo. Nesses espaços, ocorrem disputas pela hegemonia política e a fabricação de um consenso como forma de dominação política estruturada na capacidade de persuasão. Os meios de comunicaçáo também possuem certa centralidade social, associada a seu papel no processo de socializaçấo contemporâneo, a partir da qual o indivíduo internaliza a cultura de seu grupo e as normas sociais. $\mathrm{Na}$ esfera política, explica Lima (2000), a centralidade da mídia decorre de sua potencialidade para construção da realidade por meio da representação transmitida em seus canais sobre os diferentes aspectos da vida humana.

A partir das ideias de Gramsci, Lima (2000) argumenta que os meios de comunicação eletrônicos transformam a mídia em um aparelho privilegiado na articulação hegemônica (e contra-hegemônica) e espaço de disputas políticas por meio das representaçōes veiculadas. Nas democracias contemporâneas, o enfraquecimento dos partidos políticos como mecanismos de representação política e defesa de ideologias permite que, em muitos casos, os veículos de comunicaçáo sirvam de mediadores entre os candidatos e os eleitores. Náo obstante, apesar de a mídia ter papel importante no processo eleitoral, os partidos continuam sendo essenciais como plataforma política e articulação de alianças.

Castells (1999, p. 366) argumenta que a formação da sociedade em rede traz consigo um "esvaziamento do contrato social entre capital, trabalho e Estado [que] envia todos de volta para a casa para lutar por seus interesses individuais". Nesse contexto, existe uma transformação das práticas políticas e dos processos democráticos, uma vez que as novas tecnologias de comunicação e informação tornam-se novas ferramentas para a busca pelo poder dos atores políticos e circulação de informação política. Para Castells (1999, p. 367), essa transformação tem o nome de "política informacional", que introduz novas regras no jogo político, tornando a mídia importante meio para "adquirir ou exercer poder" sem, contudo, reduzir a política à pura e simples divulgação simbólica através dos sons e das imagens midiáticas. Essa nova configuração permite a incorporaçâo de novas práticas, tais como o marketing político, que, nas democracias ocidentais, ganham importância na condução do comportamento político e na orientação das açôes estatais, principalmente na condução de PP. A ação do marketing vai além do período eleitoral e acaba por influenciar no modelo de gestão pública, orientando as práticas das PP, que podem ser utilizadas como ferramentas de promoção eleitoral de forma a agregar maior capital político para seu gestor. ${ }^{1}$

Apesar de a mídia e seus diferentes veículos serem importantes dentro da atual configuração política, é preciso indicar que a política não se subordina a ela. Miguel (2002) sustenta que o rápido desenvolvimento tecnológico das comunicações trouxe importantes mudanças no ambiente político ao longo do século XX (e também agora no início do século XXI), como um novo mecanismo e espaço de contato entre líderes políticos e os cidadáos, a formulação de uma nova relação entre a população e os temas públicos (incluindo as PP), e até criando uma nova dinâmica no processo de governança $\mathrm{e}$ accountabillity (mecanismo de prestaçấo de contas perante irregularidades governamentais).

De acordo com Miguel (2002, p. 156), os meios de comunicação de massa "são vistos como meros transmissores dos discursos dos agentes e das informaçōes sobre a realidade, neutros e, portanto, negligenciáveis". Uma das exceçóes a essa neutralidade é o trabalho de Sartori (2001), que, atento às transformaçôes da política contemporânea, indica que os governos sofrem forte pressão da mídia, ficando sob um "controle excessivo" da opiniâo pública. Tal controle diminui a possibilidade de ação racional e planejamento de médio e longo prazo, interferindo ainda sobre as decisóes admi- 
nistrativas, uma vez que a prática estatal fica sob os holofotes da mídia, exigindo respostas rápidas às demandas surgidas nos noticiários. Ainda segundo Sartori (2001), a divulgação da mídia (tratando especificamente da televisão) é incapaz de promover uma reflexão crítica, exercendo, portanto, influência nociva ao universo da política.

$\mathrm{Na}$ área de comunicação social, existe um campo maior de estudo dessa zona de fronteira de conhecimentos. Contudo, seus respectivos trabalhos tendem a exagerar a influência da mídia, relegando a ela um poder maior que os resultados empíricos apontam. Apesar de a política sofrer influência da mídia, ela possui uma lógica própria: utilizando o conceito de campo de Pierre Bourdieu, Miguel (2002) sustenta que, apesar da inegável centralidade da mídia na sociedade contemporânea, ela e a política formam dois campos diferentes, guardando certo grau de autonomia, sendo que a influência de um sobre o outro se torna um "processo de mão dupla”. A maior participação dos meios de comunicação estaria ancorada na formação do capital político. A visibilidade na mídia confere um capital que pode ser convertido em votos ou status político, dois importantes fatores para os atores que atuam dentro no campo político. Outro momento de interferência do campo midiático no político é o controle da agenda. As questóes destacadas pelos veículos de comunicaçáo ganham evidência no debate público, exercendo pressão sobre a ação governamental, que precisa então "dar respostas às demandas populares". Nesse sentido, Miguel (2002, p. 171) argumenta que a mídia tem a capacidade de formular ou reformular as preocupaçóes e demandas sociais, ao trazer à tona aspectos que passam a ser percebidos tanto pela populaçáo quanto pelos líderes políticos e funcionários públicos, "que se veem na obrigação de dar uma resposta àquelas questóes”.

Para Miguel (2002), a mídia não se limita à definição da agenda (cf. o célebre conceito de agenda-setting cunhado por McCombs e Shaw, 1972), mas também opera na construção de esquemas narrativos que permitem interpretar os acontecimentos por meio de enquadramentos (framming). Em sociedades em que cada vez mais a população tem menos interesse pelos assuntos políticos, reporta- gens e noticiários podem tornar-se "atalhos informacionais" pelos quais o cidadão vai criar sentido para a realidade política e formar sua opinião. Porém, em geral, os canais de comunicação tendem a destacar as fontes institucionais, com pouco espaço para discursos alternativos, favorecendo a manutenção de um status quo. Isso, de certa forma, limita a capacidade de interferência da mídia na prática do campo político.

Nesse sentido, Miguel (2002) sustenta que existe uma influência real da mídia sobre o campo político. Contudo, essa influência é exercida de diferentes formas e atinge resultados diferenciados sobre os atores e instituiçóes políticas. Isso quer dizer que a pressão da mídia encontra limites que se estendem desde sua dependência do campo político como fonte de informação, recursos de financiamento e interesses políticos (como, por exemplo, concessão de transmissão de sinal), até as ingerências do campo econômico sobre sua atuação e cobertura da política, isto é, interesses de anunciantes que podem interferir no formato de cobertura da empresa de comunicação.

\section{Mídia e políticas públicas}

Em nossa sociedade, os meios de comunicação possuem uma grande importância para o jogo político: como espaço de disputa de imagens e capital político; como mecanismo de intermediação entre as instituições políticas, atores políticos e cidadãos; como fonte de informação política; e/ou como um mecanismo de pressão da opinião pública e grupos de interesses. De acordo com Miguel (2002), a ciência política, no entanto, parece não ter contabilizado a mídia como uma importante variável (dependente e independente) para a compreensão do processo de $\mathrm{PP}$, sendo incapaz de perceber a mídia como importante e influente peça do jogo político.

Celina Souza (2006) aponta que o ressurgimento da importância das PP como campo de conhecimento nas últimas duas décadas está relacionado a dois fatores: 1) adoção de políticas restritivas de gastos, que limitaram o desenho (design) e a execução de PP; 2) e novas visóes sobre o papel dos governos na condução de suas práticas políticas. Esses fatores 
ganham maior relevância a partir da maior visibilidade midiática do campo político, ampliando os espaços de cobertura jornalística para a açáo estatal, principalmente em estados democráticos.

Já indicamos que, no Brasil, o tema começou a ganhar destaque com a luta pela redemocratizaçáo e formação de várias frentes de organização da sociedade civil pela promoçáo da cidadania. Esse processo consolidou-se com a Constituição de 1988, momento em que diversos grupos participaram ativamente do debate sobre o papel constitucional do Estado na promoçấo do bem-estar social. Contudo, a partir do governo Collor (1990-1992), começou a se esboçar uma nova articulaçáo de desmantelamento da rede de proteção social e adoção de práticas chamadas de neoliberais, restringindo a ação estatal na promoção de políticas sociais.

Nesse mesmo período, os meios de comunicação, principalmente a televisão (e agora a internet), se consolidam como espaços de informação política e de relação social (campo de disputa simbólica). Com a redemocratização, os temas políticos ganharam espaço e relevância na agenda da mídia. Assim, as PP também passaram a ser apresentadas, e consequentemente debatidas, nos canais de comunicação, ganhando nova conotação política para além de sua ideia inicial de intervenção técnico-científica dos governos.

A literatura da área desenvolveu diferentes formas de análises de PP, sintetizadas por Souza (2006) em oito modelos:

1. O primeiro modelo é o tipo de PP desenvolvida por Theodore Lowi a partir da máxima que a política pública faz a politica; essa tipologia indica que as PP podem seguir quatro formatos: distributivas, regulatórias, redistributivas e constitutivas.

2. O segundo modelo é o do incrementalismo, ou a compreensão das PP como um processo incremental definido anteriormente, no qual o governo tem pouca influência, isto é, as decisóes tomadas no passado constrangem novas postulações.

3. O terceiro modelo é o de ciclo, que é a compreensão das PP como um ciclo deliberativo formado por vários estágios, estabelecendo um processo dinâmico - nesse modelo, a mídia entra como um ator do processo de deliberaçáo, principalmente na definição da agenda (agenda-setting). Com relaçâo aos referidos estágios, estes são: definição da agenda, identificação de alternativas, avaliação das opçóes, seleção das opçóes, implementação e avaliação. Cabe ressaltar que não existe um consenso firmado na literatura sobre esses estágios (Souza, 2006; Frey, 2000).

4. O quarto modelo é o garbage can (lata de lixo): entendimento de que as escolhas de PP são delimitadas pelas poucas soluçóes existentes diante dos vários problemas apresentados.

5. O quinto modelo é o de coalizão de defesa, o qual compreende que as PP deveriam ser concebidas como um conjunto de subsistemas relativamente estáveis, que se articula com os acontecimentos externos que criam restriçốes a sua execução.

6. O sexto modelo envolve as arenas sociais. Aqui, as PP são entendidas como açôes empreendedoras dos atores políticos, que destacam algum problema que precisa ser resolvido por meio de uma PP. Percebe-se, a partir desse modelo, que a mídia pode influenciar determinada PP ao destacar, em sua programação, certos aspectos que podem orientar a percepção dos policy makers, tais como a divulgação de indicadores desfavoráveis para administração pública em determinados setores estratégicos, desastres e repetiçáo de problemas (como no caso das enchentes) ou com o anúncio de resultados medíocres alcançados pela política em gestão. Nesse modelo, os empreendedores formam redes sociais que se articulam politicamente para a criação de determinadas PP.

7. O sétimo modelo trata do equilíbrio interrompido, no qual a PP se caracteriza por períodos de estabilidade que, em instantes de mudança política, sofrem alteraçóes. Esse modelo indica que um sistema político pode atuar de forma incremental, assim como permite mudanças radicais (em épocas de instabilidade política). Nesse modelo, a mídia assume papel fundamental na construção da imagem de determinada PP (policy image) frente cada novo contexto político.

8. E, por fim, há o modelo influenciado pelo novo gerenciamento público (new public manegement): com a restriçáo dos gastos públicos, as PP passam a ser gerenciadas de acordo com sua eficiência e credibilidade. A ideia é afastar o irracionalismo da 
ação coletiva. Contudo, mesmo nesse modelo, a mídia assume papel importante, pois uma cobertura favorável a determinada PP pode aferir-lhe credibilidade - e a recíproca é verdadeira.

Diante desses modelos, podemos concordar com Miguel (2003) e avaliar que a mídia é um fator de influência no processo das PP no jogo político contemporâneo, podendo ser um relevante ator que pode interferir na formação da agenda política, na percepção de certos problemas sociopolíticos, além de configurar-se em uma arena de disputa de discursos entre os outros atores, criando novos canais para o alargamento da democracia e de representação política além das formas tradicionais. Outro papel importante desempenhado pela mídia é sua participação na definição da agenda dos temas relevantes para a discussão na esfera pública. Ainda, o espaço público midiático torna-se uma área privilegiada de produção e divulgação de informaçóes políticas que possibilita maior transparência da administração pública, favorecendo a criação de lugares para o debate e crítica das PP (apresentando e avaliando seus resultados) e a geração de esferas públicas concorrentes além das tradicionais, em que diferentes grupos da sociedade podem expressar suas ideias e opinióes de forma pública, principalmente com o desenvolvimento e comercialização do acesso à internet.

Com o desenvolvimento das TICs, a relação política ganha novo grau de complexidade, pois as características comunicacionais dessas recentes tecnologias permitem uma nova dinâmica; agora, é possível a execução de novas práticas políticas que rompam com o monopólio das grandes empresas de comunicação como esfera principal de produção, transmissão e circulação de informaçóes, políticas inclusive. Nessa nova dinâmica, ainda, surgem novos meios e formatos de comunicação que são apropriados pelos atores políticos em suas práticas. A princípio, os chamados ciberotimistas (cf. Lemos e Lévy, 2010) acreditavam que seria uma nova fase da política, em que as instituições perderiam poder para a ação mais descentralizada do cidadão comum na formação de uma ciberdemocracia.

Entretanto, os agentes e as instituiçóes também se apropriaram dessas ferramentas tecnológi- cas, adaptando suas práticas para esses novos meios. Os governos apropriam-se das novas tecnologias para desenvolver serviços públicos para o cidadão, ancorados na lógica do aumento da eficiência da gestão pública e no processo de desburocratização. São criados mecanismos de controle das contas públicas (exemplo: Portal Transparência Brasil), acesso a serviços públicos (exemplo: emissão de documentos), informaçôes sobre serviços públicos e, em especial, arrecadação de tributos (exemplo: Imposto de Renda).

Os diferentes canais de comunicação são importantes ferramentas e espaços que podem possibilitar que o campo das PP, geralmente restrito a atores institucionais que participam do processo decisório, ganhe visibilidade e permita que os cidadãos possam ter mais informaçóes, além de poder participar de alguma etapa de seu ciclo, principalmente pelos mecanismos interativos e colaborativos das TICs. Podem-se citar como exemplos: 1) o Orçamento Participativo Digital em Belo Horizonte, no estado de Minas Gerais, onde a população pode participar da discussão de alguns pontos do orçamento pela via digital (Sampaio et al., 2010); 2) a pesquisa de Araújo et al. (2011) a respeito da criação de blogs (e outros fóruns de debate) sobre políticas culturais pelo Ministério da Cultura do Brasil, nos quais o cidadão/usuário pode acompanhar o desenvolvimento da política e emitir opinióes; ${ }^{2} 3$ ) o estudo de Egler (2010) sobre a atuaçáo de redes tecno-sociais como a Associação Brasileira de Organizaçóes Não Governamentais (Abong), que utiliza os dispositivos da internet para articular sua ação sobre as PP. Esses três exemplos ilustram como a mídia (digital) pode ser um mecanismo de aumento da participação popular no processo de PP, contribuindo para sua democratização e da sociedade e maior eficiência.

\section{Aproximaçóes entre mídia e políticas públicas}

Stromberg (2001) sustenta que os meios de comunicação de massa podem influenciar as PP de duas formas: 1) no âmbito da competição eleitoral, em que as políticas são apresentadas como produtos dentro de mercado eleitoral (seguindo a lógica econômica downsiana); 2) como referência (feedback) 
para avaliaçáo dos resultados e popularidade de determinadas políticas. Essas duas formas, apesar de indicarem importantes caminhos de investigação, são insuficientes para explicar as relaçóes entre o campo midiático e o campo das PP, uma vez que, a partir da análise da literatura, podemos identificar outras maneiras de interferência da mídia, principalmente em regimes democráticos, que têm nos canais de comunicação o principal palco para a visibilidade das ações políticas e arena de disputa de discursos políticos em busca de capital político para sua intervenção. Extrapolando a abordagem de Stromberg (2001), a inter-relação entre mídia e PP pode ser percebida em diferentes etapas, conforme sistematizado no Quadro 1, que utiliza o modelo de análise do ciclo de PP para realizar essas relaçóes.

Quadro 1

\section{Relações entre Mídia e Políticas Públicas}

Etapa Influência Atuaçáo da mídia Características

$\begin{array}{llll}\text { 1. Definição da agenda } & \begin{array}{l}\text { Direta e/ou } \\ \text { indireta }\end{array} & \begin{array}{l}\text { Visibilidade para determinados } \\ \text { problemas da sociedade. }\end{array} & \begin{array}{l}\text { Pressão da opiniáo pública sobre agentes da } \\ \text { realce para temas com maior apelo popular. }\end{array}\end{array}$

2. Identificação de Indireta Visibilidade para determinadas Disputa por espaço dentro dos canais alternativas Indireta alternativas apresentadas. midiáticos das alternativas.

3. Avaliação das opçóes Indireta

4. Seleção das opçôes Indireta

5. Implementação

Direta e/ou

indireta

6. Avaliação e monitoramento

Direta e/ou indireta
Visibilidade para que algumas opçôes consigam ganhar consenso ou aceitação.

Visibilidade para as opçóes apresentadas pelos agentes políticos.

Visibilidade para a implementação e execução de determinada PP.
Disputa pela legitimidade das opçôes em disputa.

O espaço midiático pode ser utilizado para os grupos de interesse indicarem suas preferências diante das opçóes apresentadas.

A cobertura da mídia de determinada PP pode ser positiva ou negativa, funcionando como um espaço de disputa simbólica entre os diferentes atores envolvidos.

A divulgaçáo de resultados positivos ou negativos pela mídia de determinada PP é essencial para que o seu executor possa ampliar ou diminuir seu capital político, para sua continuidade, sua ampliação e receber mais recursos.

Fonte: elaboração dos autores.

O ciclo detalhado no Quadro 1 permite observar que o elemento principal da influência da mídia encontra-se na sua capacidade de visibilidade (ou não) dos problemas sociais, das alternativas apresentadas, das opções em pauta, de sua implementação e a avaliação e monitoramento dos resultados alcançados pela PP. A diversidade de PP, a complexidade da sociedade e as formas de atuação das empresas de mídia (que privilegiam eventos que acarretem um em aumento da audiência) possibilitam que apenas alguns elementos em torno do ciclo de PP ganhem destaque nos canais de comunicação. A maioria das práticas de $\mathrm{PP}$, principalmente nas etapas intermediárias do ciclo (o processo decisório), não tem vi- 
sibilidade. Dessa forma, como argumentou Rubim (2001) ao trabalhar com o conceito de telerrealidade para explicar o poder de influência da televisão na sociedade contemporânea, as ações desenvolvidas "inexistem" para grande parte da população, que somente consegue perceber como verdadeiro o que está dentro dos noticiários midiáticos.

Essa característica indica que a grande maioria das PP não tem espaço (visibilidade) na mídia e, quando o tem, devem atender aos critérios de noticiabilidade dos veículos de comunicação ou atender a interesses de grupos que atuam politicamente em torno de temas específicos, os quais utilizam os holofotes da mídia para realçar ou incorporar algum tema na agenda social e política ou apresentaçấo de alguma proposta/soluçáo que atendam suas preocupaçóes.

Do Quadro 1 também podemos inferir três momentos de maior inter-relação: 1) na definição da agenda; 2) na fase de implementação; 3) na avaliaçấo e monitoramento dos resultados alcançados. A maioria dos estudos existentes centra sua análise no primeiro momento, destacando o poder da mídia sobre a formação da agenda política. Nesses estudos, não existem preocupação específica quanto à interferência (ou náo) da cobertura midiática sobre as PP, porque são voltados para tentar avaliar o poder do agenda-setting.

Walgrave e Aelst (2006), ao avaliar o poder de agenciamento da mídia sobre a agenda política, indicam que as pesquisas realizadas apresentam resultados contraditórios, sendo que alguns estudos indicam modesto impacto da mídia (de massa) sobre a agenda política, enquanto outros sinalizam que existe forte correlação. Nesse sentido, os autores aferem que o impacto do agenciamento da mídia existe, mas é limitado às características do sistema político, do meio de comunicaçáo, da relevância do tema/problema (issue), sua exposição e em momentos de crise.

É possível identificar três principais explicaçôes sobre os motivos que levam os atores políticos a adotarem temas apresentados pela mídia. (1) Pode-se afirmar que, assim como o cidadáo comum é afetado pelo noticiário da mídia, os agentes políticos também o são. (2) Nas democracias, os meios de comunicação são arenas nas quais os atores políticos disseminam ideias políticas e propostas que são lançadas, testadas e contestadas; daí, a partir de sua repercussão na cobertura midiática, eles podem avaliar o uso ou não de determinadas propostas. (3) A associação entre a cobertura da mídia e a opinião pública. Se a mídia afeta ou não a opinião pública é irrelevante, explicam Walgrave e Aelst (2006), porque o que conta é que os atores acreditam que ela determina os assuntos públicos prioritários. Isso quer dizer que o destaque da mídia para determinada questão torna-se um indicativo das preocupações da opinião pública. Assim, os agentes políticos não reagem à mídia, mas a uma expectativa da percepção da opinião pública, construindo suas estratégias políticas de forma a atender essa demanda.

Nesse sentido, Walgrave e Aelst (2006) identificam que a cobertura dos meios de comunicação de massa pode assumir reações políticas em duas dimensões: simbólica e substancial. A primeira indica uma reação retórica frente à "pressão" da mídia, mas com pouca efetividade sobre a execução das políticas, enquanto a segunda, substancial, refere-se a mudanças efetivas a partir da cobertura de determinada questão. Nesse quadro, os autores propóem um modelo com cinco tipos de reaçóes políticas à cobertura midiática sobre determinada questão (issue): 1) não reação; 2) reação simbólica rápida; 3) reação substancial lenta; 4) reação substancial rápida; 5) reação simbólica lenta. Essas reaçóes variam de acordo com o contexto político e os inputs da mídia.

Em relação à fase de implementação das $\mathrm{PP}$, ainda náo existem estudos que sistematizem e/ou mensurem a inter-relação PP e mídia, pois tais estudos, como já indicado, são voltados para os aspectos institucionais e formais das políticas. Como destaca Celina Souza (2003), existe a necessidade de incorporar na agenda de pesquisa desse campo novos fenômenos que interferem na execução e implementaçáo de PP, percebendo que o processo é mais complexo e dinâmico, onde elementos externos acabam por interferir, mesmo que indiretamente, na consolidação de suas práticas e ações. Nesse caso, a mídia, através dos seus diferentes dispositivos, pode ser uma importante variável externa a ser mensurada nos estudos sobre a execução de PP.

A visibilidade de uma PP pode ser fundamental para que ela seja implementada de forma 
eficiente. Por isso, a cobertura da mídia (positiva ou negativa) de uma PP em implementação serve como um campo de disputa simbólica entre os atores envolvidos. Além de permitir maior transparência na implementação, importante característica para garantir maior eficácia de uma PP, uma abordagem favorável possibilita que determinada PP consiga ser implementada com mais facilidade e apoio dos agentes envolvidos. Entretanto, se for negativa, uma PP pode encontrar sérios obstáculos que podem inviabilizar sua realizaçáo ou atrasar sua implementação.

No momento da avaliação e monitoramento dos resultados, a mídia pode implicar na forma pela qual a populaçáo percebe os benefícios ou náo de determinada política. Nem todas as pessoas são beneficiadas, pelo menos diretamente, pelas PP em geral, que tem caráter setorial. Assim, grande parte da população não tem informaçóes sobre o andamento de determinada política, dependendo da visibilidade e enquadramento que a mídia dá a determinados eventos. Por mais que determinada política alcance resultados positivos do ponto de vista técnico, ela somente poderá ser convertida em capital político para seu realizador se for percebida pela população. Boas políticas com boas avaliaçôes técnicas podem perder sua continuidade caso náo obtenham visibilidade positiva e apoio da opinião pública.

Como ressalta Faria (2005), as avaliaçóes de PP ganharam relevância amparadas pela necessidade de modernizaçâo da gestão pública e reforma do Estado. Como última etapa do ciclo de PP, a avaliação serve para mensurar os resultados alcançados, fornecer subsídios para correçôes, ajustes e desenhar novas PP. As avaliações também servem como um mecanismo de prestação de contas e responsabilização dos agentes públicos encarregados. Dessa forma, como indica o autor, prevalece um viés normativo que prioriza os aspectos técnicos e uma ênfase no papel gerencial, isto é, uma leitura positivista (e ingênua) das PP, desprezando fatores (como a mídia) que podem exercer influência nesse processo.

Faria (2005) assinala que existe a necessidade de que os estudos sobre a avaliação de PP devem ir além do modelo instrumental e gerencialista, sendo necessário incorporar, nas pesquisas, elementos do jogo político de disputa pelo poder, que passa pela disputa eleitoral, pela competição intragovernamental dos órgãos envolvidos, luta pela distribuição de recursos, alocação de apoios políticos, entre outros elementos.

\section{Consideraçóes finais}

Apesar de as PP serem vistas, de uma maneira simplista, como intervençóes técnicas dos governos, comandadas por uma racionalidade institucional específica voltada para a eficiência de seus resultados, percebe-se, na prática, que existem influências de diversos atores, alguns não institucionais (formais) como a mídia, que vão tecer influência e pressionar a sua concepção, seu formato ou mesmo interferir no modo como serão avaliados seus resultados.

Neste artigo, buscou-se fazer uma aproximação entre mídia e PP pelo viés do modelo do ciclo de PP, identificando três momentos de maior influência do primeiro sobre o segundo. Contudo, como apontado no próprio texto, existem outros modelos de análise de PP que permitem aproximaçóes diversas. Gostaríamos de destacar, por fim, outras possibilidades já indicadas ao longo deste texto:

1. PP como ferramenta de marketing político: com a profissionalizaçáo das campanhas eleitorais e o desenvolvimento da atividade de marketing político, os canais de mídia se tornam palcos privilegiados de comunicação das campanhas com o eleitorado. Nesse sentido, algumas $\mathrm{PP}$ ou propostas são "vendidas" (veiculadas) nas propagandas eleitorais dos candidatos, esvaziando seu critério "técnico" e valorizando seu aspecto simbólico. A necessidade dos governos de legitimarem suas açóes em regimes democráticos, ou mesmo confirmarem seu capital político, fazem com que muitas das PP sejam escolhidas ou desenvolvidas com um viés exclusivamente político, o que leva ao esvaziamento de seus elementos técnicos e coloca em risco sua eficiência e eficácia.

2. O caráter dialético entre opinião pública e PP: a partir das características apontadas no item anterior, pode-se observar, com base nas consideraçōes de Howlett (2000), que existe uma relação dialéti- 
ca entre ambas. Mesmo que a opinião pública, influenciada pela cobertura da mídia, não determine os resultados de uma política, ela desempenha um papel indireto na formação das políticas e representa um elemento importante nos subsistemas de políticas. Por outro lado, as PP também podem ser utilizadas como forma de manipulação da opinião pública, sendo a mídia utilizada como mecanismo de mediação.

3. Manutenção do caráter normativo das PP: o caráter comercial que regula a cobertura da mídia acaba por privilegiar abordagens espetaculares sobre as PP, esvaziando a possibilidade de visão crítica e conflituosa sobre todo o processo das PP. De forma geral, a cobertura midiática não tem um caráter questionador das políticas adotadas, preferindo destacar aspectos positivos e negativos em torno de problemas ou resultados, sem, no entanto, promover um amplo debate sobre determinada política, esgotando o assunto em pontos específicos. Dificilmente os diferentes atores envolvidos, sejam eles membros da administração pública ou segmentos da sociedade civil, conseguem espaço para apresentar suas visóes e perspectivas sobre uma PP em pauta.

4. Possibilidade de maior participação da sociedade civil no processo de PP através do uso das TICs: o caráter interativo e colaborativo das novas tecnologias indicam novas possibilidades de inclusão e participação da população nas $\mathrm{PP}$, principalmente pela facilidade de comunicaçáo, maior acesso a informaçôes e menor custo de participação política. $\mathrm{O}$ uso das TICs indica um importante caminho a ser incorporado nas agendas de pesquisa, especialmente pelo rápido aumento do número de usuários e dos acessos no dia a dia das pessoas.

A partir da literatura apresentada, pode-se considerar que, apesar de não haver indicadores específicos para avaliar as interaçóes entre PP e mídia, o que sinaliza uma importante tarefa a ser incorporada na agenda de pesquisas e a execução de estudo empíricos, existe uma interferência da mídia sobre o ciclo de PP, principalmente em sociedades democráticas nas quais os meios de comunicação possuem centralidade nas relaçóes sociais, tal como a brasileira, o que sugere a necessidade de ampliação de estudos para avaliar essa relação.

\section{Notas}

1 O uso de PP como forma de ampliaçáo do capital político foi estudado em outra pesquisa (Penteado, 2001), que avaliou o uso do Plano de Assistência a Saúde (PAS) no município de São Paulo, durante a gestáo Paulo Maluf, como ferramenta de marketing político.

2 A pesquisa realizada indicou que apesar de existir ferramentas para ampliar a participação, elas são poucas utilizadas pelos cidadãos.

\section{BIBLIOGRAFIA}

ARAÚJO, R.; PENTEADO, C. L. C. \& BURGOS, R. (2011), Democracy and internet: a comparative study between portals of the ministries of culture (Brazil and Argentina). Rio de Janeiro, IPSA.

CASTELLS, M. (1999), A sociedade em rede. São Paulo, Paz e Terra.

. (2009), Communication power. Oxford, Oxford University Press.

EGLER, T. T. C. (2010), "Redes tecnossociais e democratização das políticas públicas". Sociologias, 12 (23): 208-236.

FARAH, M. (2007), "Parcerias, arranjos institucionais e políticas públicas no nível local de governo", in E. Saraiva e E. Ferrarezi, Politicas públicas - Coletânea volume 1, Brasília, Enap.

FARIA, C. A. P. (2005), "A política da avaliação de políticas públicas”. RBCS - Revista Brasileira de Ciências Sociais, 20 (59): 97-110.

FREY, K. (200), "Políticas públicas: um debate conceitual e reflexóes referentes à prática da análise de políticas públicas no Brasil". Revista Planejamento e Politicas Públicas, 21: 211-259.

GOMES, W. \& MAIA, R. C. M. (2008), Comunicação e democracia: problemas e perspectivas. São Paulo, Paulus.

HOWLETT, M. (2000), "A dialética da opinião pública: efeitos recíprocos da política pública e da opinião pública em sociedades democráticas contemporâneas”. Opinião Pública, 6 (2): 167-186. 
LEMOS, A. \& LÉVY, P. (2010), O futuro da internet: em direção a uma ciberdemocracia planetária. São Paulo, Paulus.

LIMA, V. A. (2000), Midia: teoria e política. Sáo Paulo, Fundação Perseu Abramo.

LIPPMANN, W. (1997), Public opinion. Nova York, Free Press.

MCCOMBS, M. \& SHAW, D. (1972), "The agenda setting function of mass media". Public Opinion Quartely, 36.

MIGUEL, L. F. (2002), "Os meios de comunicaçấo e a prática política”. Lua Nova, 55-56: 155-184.

(2003), "Representação política em 3-D: elementos para uma teoria ampliada da representação política". RBCS - Revista Brasileira de Ciências Sociais, 18 (51): 123-140.

NORIS, P. \& CURTIS, J. (2008), "Getting the message out: a two-step model of the role of the internet in campaign communication flows during the 2005 British General Election". Journal of Information Technology \& Politics, 4 (4): 3-13.

PENTEADO, C. L. C. (2001), Marketing politico $x$ politicas públicas: um estudo de caso do PAS. São Paulo, dissertação de mestrado, PUC. . (2008), "Blogs e ação política". Anais

do IX Congreso da Asociaón Latinoamericana de Investigadores de Comunicación (ALAIC), Atizapán de Zaragoza.

. (2009), "Novas práticas políticas na internet: estudo do Blog Fatos e Dados. Anais do III Congresso da Associação Brasileira dos Pesquisadores em Comunicação e Política, São Paulo.

PENTEADO, C. L. C.; SANTOS, M. B. P. \& ARAUJO, R. P. A. (2009), "Metodologia de pesquisa de blogs de política: análise das eleiçôes presidenciais de 2006 e do movimento 'cansei'". Revista de Sociologia e Politica, 17: 159-181.

RANCIERE, J. (1996), "O dissenso", in A. Novaes (org.), A crise da razão, São Paulo/Brasília/Rio de Janeiro, Cia. das Letras/Ministério da Cultura/Fundação Nacional de Arte.

RUBIM, A. A. C. (2001), Comunicação e política. São Paulo, Haker Editores.
. (2000), "Contemporaneidade como Idade Mídia”. Interface (Comunicação, Saúde e Educação), 4: 25-36.

SAMPAIO, R. C.; MAIA, R. C. M. \& MARQUES, F. P. J. A. (2010), "Participação e deliberação na internet: um estudo de caso do Orçamento Participativo Digital de Belo Horizonte". Opinião Pública, 16 (2): 446-477.

SARTORI, G. (2001), Homovidens: televisão e pós-pensamento. Bauru, Edusc.

SOUZA, C. (2003), “'Estado do Campo' da pesquisa em políticas públicas no Brasil”. RBCS - Revista Brasileira de Ciências Sociais, 18 (51): 15-20.

(2006), "Políticas públicas: uma revisão da literatura”. Sociologias, (8) 16: 20-45.

STROMBERG, D. (2001), "Mass media and public policy". European Economic Review, 45 (46): 652-663.

SUBIRATS, J. (2008), Análisis y gestión de politicas públicas. Barcelona, Editorial Ariel.

THOMPSON, J. B. (1998), Mídia e modernidade: uma teoria social da mídia. Petrópolis, Vozes.

WALGRAVE, S. \& AELST, P. V. (2006), "The contingency of the mass media's political agenda setting power: toward a preliminary theory". Journal of Communication, 56: 88-109. 


\section{MÍDIA E POLÍTICAS PÚBLICAS: POSSÍVEIS CAMPOS EXPLORATÓRIOS}

\section{Claudio Camargo Penteado e Ivan Fortunato}

Palavras-chave: Políticas públicas; Mídia; Comunicação; Estado.

A centralidade da mídia na sociedade brasileira confere aos meios de comunicação importante papel na dinâmica social contemporânea, cuja influência alcança diversos campos da atividade humana, inclusive o político. $\mathrm{O}$ debate sobre políticas públicas tem dominado grande parte da agenda das ciências sociais. Em geral, as abordagens preservam uma tendência institucionalista, focando suas análises sobre os processos decisórios e/ou avaliativos. No entanto, observamos uma lacuna nas pesquisas desenvolvidas, que é a de verificar a participação da mídia no ciclo das políticas públicas. Neste artigo buscamos inferir a relação entre a cobertura da mídia e o processo dessas políticas na sociedade brasileira contemporânea.

\section{MEDIA AND POLICY: SOME POSSIBLE EXPLORATORY FIELDS}

\section{Claudio Camargo Penteado and Ivan Fortunato}

Keywords: Public Policies; Media; Communication; State

The centrality of the media in the Brazilian society assigns to the means of communication an important role in contemporary social dynamics, whose influence attains several fields of human activity, including the political. The debate on public policies has been dominating most of the agenda of the social sciences. In general, the approaches preserve a tendency of institutional character, with the analyses centered on decisional or evaluative processes. The article observes, however, a gap in the researches developed on the theme, i.e., the lack of an assessment of the media's participation on the cycle of the public policies. In this sense, the article seeks to infer the relations between media coverage and public policies processes in contemporary Brazilian society.

\section{MÉDIAS ET POLITIQUES PUBLIQUES: DES POSSIBLES DOMAINES DE RECHERCHE}

\section{Claudio Camargo Penteado et Ivan Fortunato}

Mots-clés: Politiques publiques; Médias; Communication; État.

Le rôle central des médias dans la société brésilienne confère aux moyens de communication un rôle important dans la dynamique sociale contemporaine, dont l'influence a atteint plusieurs champs de l'activité humaine, y compris le politique. Le débat sur les politiques publiques domine une grande partie de l'ordre du jour des sciences sociales. En général, les approches préservent une tendance institutionnaliste, en concentrant leurs analyses sur les procédures décisionnelles et/ ou d'évaluation. Nous avons cependant observé une lacune dans les recherches développés, qui est la vérification de la participation des médias dans le cycle des politiques publiques. Dans cet article, nous essayons de déduire la relation entre la couverture médiatique et le processus de ces politiques dans la société brésilienne contemporaine. 